\title{
PENGARUH BAURAN PEMASARAN TERHADAP DAYA SAING INDUSTRI KERAJINAN TEMBAGA (Studi Kasus Pada Pengrajin Di Desa Tumang Kecamatan Cepogo Kabupaten Boyolali)
}

\author{
Hanifah Millatina ${ }^{1}$, Nuning Lisdiana ${ }^{2}$, Hari Purwanto ${ }^{3}$ \\ hanifahmilla36@gmail.com \\ Universitas Boyolali
}

\begin{abstract}
The problem in this study is the increasing competition in the world of copper handicraft industries in Tumang Village, Cepogo District, Boyolali Regency both in the fields of production and marketing. This is evident in the increasingly fierce competition lately. The purpose of this study is to find out how the marketing mix (product, price, place and promotion) influences the competitiveness of the copper industry. In this study, the subjects of the study were the craftsmen of the copper handicraft industry in Tumang Village, Cepogo District, Boyolali Regency. A sample of 50 craftsmen.

The method used in this study is explanatory survey, namely by using a questionnaire as a means of data collection and data analysis techniques using multiple linear regression.

Partial results of the product variable, price and place do not significantly influence competitiveness. While the promotion variable has a significant positive effect on competitiveness. And simultaneously showing product, price, place and promotion variables have no significant effect on competitiveness.

Keywords: marketing mix, product, price, place, promotion, competitiveness
\end{abstract}

\section{PENDAHULUAN}

Indonesia memasuki era perdagangan bebas dengan kebijakan pemerintah yang tidak melakukan diskriminasi terhadap ekspor maupun impor. Hal ini menyebabkan terjadinya pembaharuan yang signifikan dan berdampak bagi perekonomian baik di dalam negeri maupun di luar negeri. Dampak yang sangat terlihat adalah semakin ketatnya persaingan di setiap sektor. Usaha Mikro, Kecil dan Menengah (UMKM) dan Industri kini harus mulai diperhatikan oleh pemerintah untuk mendukung perekonomian negara secara optimal serta memaksimalkan sumber daya dan potensi yang dimiliki di setiap daerah di Indonesia. UMKM dan Industri memiliki peran yang sangat penting dalam pertumbuhan ekonomi serta untuk memberdayakan sumber daya baik sumber daya alam maupun sumber daya manusia di setiap daerah.
Berdasarkan catatan IMD (Outlook Ekonomi Indonesia Bank Indonesia, 2008) rendahnya kondisi daya saing Indonesia, disebabkan oleh buruknya kinerja perekonomian nasional yang terbagi dalam empat hal utama yaitu buruknya kinerja perekonomian nasional, buruknya efisiensi kelembagaan pemerintah, lemahnya efisiensi usaha dan keterbatasan infrastruktur.

Menurut Tambunan (2002:1) Usaha mikro, kecil dan menengah (UMKM) khususnya usaha kecil di negara berkembang sering dikaitkan dengan masalah ekonomi dalam negeri seperti tingginya tingkat kemiskinan, besarnya jumlah pengangguran, pendidikan yang rendah, ketimpangan distribusi pendapatan, proses pembangunan yang tidak merata antar daerah dan kota. Hal ini berarti keberadaan UMKM diharapkan dapat memberi kontribusi positif dan signifikan terhadap upaya penanggulangan masalah tersebut. 
Industri kecil dan menengah memiliki jumlah usaha yang banyak. Dimana mereka memberikan kontribusi yang besar terhadap penciptaan lapangan pekerjaan dan dapat menjadi sumber pendapatan utama, khususnya bagi daerah pedesaan dan rumah tangga golongan ekonomi lemah dan dapat meningkatkan mobilitas domestik. Kerajinan logam di Desa Tumang sudah ada sejak dulu. Sebagai pekerjaan kreatif yang turun temurun dari nenek moyang. Dulu pada awalnya para pengrajin hanya membuat barang-barang perkakas rumah tangga sesuai dengan permintaan lokal. Tapi hal itu tidak berlaku lagi saat ini, bukan hanya produksi perkaskas rumah tangga saja yang dihasilkan oleh pengrajin Desa Tumang, dewasa ini Desa Tumang disebut Sentra Kerajinan Tembaga dimana para pengrajin membuat berbagai macam kerajinan dari tembaga kuningan serta alumunium. Dengan pangsa pasar yang semakin melebar dan meluas, baik di dalam maupun luar negeri. Para pengrajin kini mampu melayani berbagai macam bentuk pesanan sesuai kebutuhan dan keinginan konsumen.

Hambatan dalam proses produksi kerajinan antara lain adalah ketersediaan modal dan bahan baku. Harga bahan baku yang mengikuti kurs dolar membuat anggaran tidak stabil dan yang menyebabkan harga produk bisa berubah sewaktu-waktu. Beberapa permasalahan lainnya antara lain adalah produk kerajinan yang beragam, ketertidaksediaan peralatan, perbedaan kompetensi para pengrajin dalam membuat produk, ketersediaan bahan baku, tempat dan saluran distribusi dari kerajinan serta promosi dalam meningkatkan penjualan.

Dengan adanya perkembangan teknologi yang semakin pesat para pengrajin mulai memanfaatkan untuk meningkatkan produktifitas melalui promosi media online. Semakin banyaknya wirausaha yang tumbuh dengan hal ini juga berdampak pada persaingan harga yang ketat dalam pelayanan konsumen. Dimana tidak menutup kemungkinan terjadi persaingan harga yang tidak sehat antar penyedia produk.

Penelitian ini menganalisa mengenai Pengaruh Bauran Pemasaran Terhadap Daya Saing Industri Kerajinan Tembaga (Studi Kasus Pada Pengrajin Desa Tumang, Kecamatan Cepogo, Kabupaten Boyolali).

\section{METODE PENELITIAN}

Menurut Sugiyono (2016:2) metode penelitian adalah cara ilmiah untuk mendapatkan data dengan tujuan dan kegunaan tertentu. Metode penelitian yang digunakan dalam penelitian ini adalah metode survei eksplanatori, dengan mengambil sampel dari suatu populasi dan menggunakan kuosioner sebagai alat pengumpul data pokok.

Populasi dalam penelitian adalah para pengrajin industri kerajinan tembaga di Desa Tumang Kecamatan Cepogo Kabupaten Boyolali yang berjumlah kurang lebih 100 orang. Dengan teknik Purposive Sampling dapat diambil sampel sebanyak 50 orang pengrajin. Adapun subjek dari penelitian adalah para pengrajin kerajinan tembaga di Desa Tumang Kecamatan Cepogo Kabupaten Boyolali.

Skala pengukuran yang digunakan pada kuesioner penelitian ini adalah skala Likert. Sedangkan teknik pengumpulan data yang dipergunakan dalam penelitian ini adalah kuesioner atau angket dan wawancara.

Operasionalisasi Variabel untuk menguji hipotesis yang akan diajukan dalam penelitian ini setiap variabel harus dipastikan, kemudian dijabarkan melalui operasionalisasi variabel. Operasinalisasi variabel penelitian ini diuraikan dalam tabel sebagai berikut:

\begin{tabular}{|l|l|l|l|}
\hline Variabel & Indikator & Sumber Data & Skala \\
\hline
\end{tabular}


EKOBIS : Jurnal Ilmu Manajemen dan Akutansi

Vol. 8 No. 1, Juni 2020

ISSN : 2502-3055

e-ISSN : 2622-17

\begin{tabular}{|c|c|c|c|}
\hline \multicolumn{4}{|c|}{ Variabel Dependen } \\
\hline $\begin{array}{l}\text { Daya Saing } \\
\text { (Y) }\end{array}$ & $\begin{array}{l}\text { Kemampuan pengrajin } \\
\text { untuk meningkatkan } \\
\text { pangsa pasar industri } \\
\text { kerajinan tembaga }\end{array}$ & Kuesioner & Ordinal \\
\hline \multicolumn{4}{|c|}{ Variable Independen } \\
\hline $\begin{array}{l}\text { Produk } \\
\text { (X1) }\end{array}$ & $\begin{array}{l}\text { Kualitas produk } \\
\text { berhubungan dengan } \\
\text { kemampuan pengrajin } \\
\text { dalam membuat produk } \\
\text { yaitu meliputi beberapa } \\
\text { aspek: } \\
\text { a.Technical competence } \\
\text { b.Marketing competence }\end{array}$ & $\begin{array}{l}\text { Skor diperoleh dari jawaban } \\
\text { responden mengenai } \\
\text { kemampuan pengrajin dalam } \\
\text { menjaga kualitas produk } \\
\text { yaitu: } \\
\text { a. Menguasai prosedur dan } \\
\text { teknik dalam proses produksi } \\
\text { b.Mampu membuat produk } \\
\text { yang diterima pasar } \\
\text { c. Mampu menjaga kualitas } \\
\text { produk yang diterima pasar }\end{array}$ & Ordinal \\
\hline $\begin{array}{l}\text { Harga } \\
(\mathrm{X} 2)\end{array}$ & $\begin{array}{l}\text { Harga produk yang } \\
\text { mampu bersaing di pasar }\end{array}$ & $\begin{array}{l}\text { Data diperoleh dari responden } \\
\text { tentang hubungan harga } \\
\text { dengan kualitas produk }\end{array}$ & Ordinal \\
\hline $\begin{array}{l}\text { Tempat/ } \\
\text { Saluran } \\
\text { Distribusi } \\
\text { (X3) }\end{array}$ & $\begin{array}{l}\text { Lokasi dan saluran } \\
\text { distribusi produk dari } \\
\text { pengrajin ke konsumen }\end{array}$ & $\begin{array}{l}\text { Data diperoleh dari responden } \\
\text { mengenai lokasi Showroom } \\
\text { dan rumah produksi kerajinan. }\end{array}$ & Ordinal \\
\hline $\begin{array}{l}\text { Promosi } \\
\text { (X4) }\end{array}$ & $\begin{array}{lr}\text { Keterkaitan } & \text { media yang } \\
\text { digunakan } & \text { pengrajin } \\
\text { dalam } & \text { memasarkan } \\
\text { produk } & \end{array}$ & $\begin{array}{l}\text { Data diperoleh dari responden } \\
\text { mengenai media apa saja yang } \\
\text { digunakan serta dapat } \\
\text { memaksimalkan pemasaran } \\
\text { produk }\end{array}$ & Ordinal \\
\hline
\end{tabular}

Teknik pengujian data yang digunakan adalah analisis deskriptif. Menurut Sanusi (2011 : 116), analisis deskriptif adalah statistik yang digunakan untuk menganalisis data dengan cara mendeskripsikan atau menggambarkan data yang terkumpul sebagaimana adanya tanpa bermaksud untuk membuat kesimpulan yang berlaku umum atau generalisasi.

Teknik uji kualitas data yang digunakan adalah uji validitas dan uji reliabilitas. Suatu penelitian dikatakan memiliki validitas tinggi apabila penelitian tersebut menjalankan fungsi ukurnya atau memberikan hasil dengan maksud digunakannya penelitian tersebut. Sedangakan tes reliabilitas adalah tes yang digunakan dalam penelitian untuk mengetahui apakah alat pengumpul data yang digunakan menunjukan tingkat ketepatan, tingkat keakuratan, kestabilan dan konsistensi dalam mengungkapkan gejala dari sekelompok individu walaupun dilaksankan pada waktu yang berbeda.

Teknik uji asumsi klasik antara lain adalah uji normalitas data, multikolinearitas, heterokedastisitas, dan autokorelasi.

Hipotesis merupakan pernyataanpernyataan yang menggambarkan suatu hubungan antara dua variabel yang berkaitan dengan suatu kasus tertentu dan merupakan anggapan sementara yang perlu diuji kebenarannya dalam 
suatu penelitian. Menurut Sugiyono (2014:63), "Hipotesis adalah jawaban sementara terhadap rumusan masalah penelitian, dimana rumusan masalah penelitian telah dinyatakan dalam bentuk kalimat pertanyaan. Dikatakan sementara, karena jawaban yang diberikan baru didasarkan teori yang relevan, belum didasarkan pada faktafakta empiris yang diperoleh melalui pengumpulan data."

Uji hipotesis secara parsial (Uji T) menurut Ghozali (2013:98), "Menguji hipotesis secara parsial guna menunjukkan pengaruh tiap variabel independen secara individu terhadap variabel dependen. Uji $\mathrm{T}$ adalah pengujian koefisien regresi masingmasing variabel independen terhadap variabel dependen untuk mengetahui seberapa besar pengaruh variabel independen terhadap variabel dependen."

Uji hipotesis secara simultan (Uji F) digunakan untuk mengetahui sejauh mana variabel-variabel bebas secara simultan (bersama-sama) yang digunakan mampu menjelaskan variabel terikat. Pembuktian dilakukan dengan cara membandingkan antara nilai kritis $F_{\text {tabel }}$ dengan nilai $F_{\text {hitung }}$ yang terdapat pada tabel analisis varian. Jika $F_{\text {hitung }}>$ $\mathrm{F}_{\text {tabel }}$ maka keputusan menolak hipotesis nol $\left(\mathrm{H}_{0}\right)$ dan menerima hipotesis alternatif $\left(\mathrm{H}_{\mathrm{a}}\right)$ artinya secara statistic data yang digunakan untuk membuktikan bahwa semua variabel bebas berpengaruh terhadap variabel terikat.

Analisis regresi linear berganda merupakan suatu teknik statistika yang digunakan untuk mencari persamaan regresi yang bermanfaat untuk meramal nilai variabel dependen berdasarkan nilai-nilai variabel independen dan mencari kemungkinan kesalahan dan menganalisa hubungan antara satu variabel dependen dengan dua atau lebih variabel independen baik secara simultan maupun parsial. Analisis regresi linear berganda digunakan untuk menguji apakah variabel independen memiliki pengaruh terhadap variabel dependen secara simultan maupun parsial.

Koefisien determinasi adalah nilai yang menunjukkan besar kontribusi pengaruh yang diberikan oleh variabel bebas terhadap variabel terikat. Nilai koefisien Nagelker's $R$ Square dapat diinterpresentasikan hampir mirip seperti nilai R Square dalam model regresi linear (Sugiyono, 2016:286)

\section{HASIL DAN PEMBAHASAN}

Pengujian Kualitas Data dengan uji validitas, jika nilai $\mathrm{r}_{\text {hitung }}>\mathrm{r}_{\text {tabel }}(\mathrm{N}=50$ $2=48, \quad \alpha=0,05$ maka $\left.\mathrm{r}_{\text {tabel }}=0,235\right)$ menggunakan uji dua arah (sig. 2-tailed) berarti butir dinyatakan valid, sedangkan jika nilai $r_{\text {hitung }}<r_{\text {tabel }}$ berarti tidak valid. Hasil uji validitas dari penelitian ini adalah sebagai berikut :

\begin{tabular}{|c|c|c|c|}
\hline \multicolumn{4}{|c|}{ Variabel Produk } \\
\hline $\begin{array}{l}\text { Pernya } \\
\text { taan }\end{array}$ & $\mathrm{r}_{\text {tabel }}$ & $r_{\text {hitung }}$ & $\begin{array}{l}\text { Ketera } \\
\text { ngan }\end{array}$ \\
\hline Butir 1 & 0,235 & 0,543 & Valid \\
\hline Butir 2 & 0,235 & 0,692 & Valid \\
\hline Butir 3 & 0,235 & 0,681 & Valid \\
\hline Butir 4 & 0,235 & 0,724 & Valid \\
\hline Butir 5 & 0,235 & 0,683 & Valid \\
\hline \multicolumn{4}{|c|}{ Sumber : Data primer yang diolah, } \\
\hline \multicolumn{4}{|c|}{$\begin{array}{l}2019 \\
\text { Berdasarkan hasil uji validitas } \\
\text { diatas dengan variabel produk diketahui } \\
\text { semua butir pernyataan } \mathrm{r}_{\text {hitung }}(0,543 \text { s.d. } \\
0,683)>\mathrm{r}_{\text {tabel }}(0,235) \text { dengan nilai } \\
\text { signifikasi } 0,05 \text { sehingga ke lima butir } \\
\text { pernyataan pada variabel produk } \\
\text { dinyatakan valid. }\end{array}$} \\
\hline
\end{tabular}


EKOBIS : Jurnal Ilmu Manajemen dan Akutansi

Vol. 8 No. 1, Juni 2020

ISSN : 2502-3055

e-ISSN : 2622-17

Variabel Harga

\begin{tabular}{|l|l|l|l|}
\hline $\begin{array}{l}\text { Pernyataa } \\
\mathrm{n}\end{array}$ & $\mathrm{r}_{\text {tabel }}$ & $\mathrm{r}_{\text {hitung }}$ & $\begin{array}{l}\text { Keterang } \\
\text { an }\end{array}$ \\
\hline Butir 6 & 0,235 & 0,670 & Valid \\
\hline Butir 7 & 0,235 & 0,431 & Valid \\
\hline Butir 8 & 0,235 & 0,681 & Valid \\
\hline Butir 9 & 0,235 & 0,639 & Valid \\
\hline Butir 10 & 0,235 & 0,659 & Valid \\
\hline
\end{tabular}

Sumber : Data primer yang diolah, 2019

Berdasarkan hasil uji validitas diatas dengan variabel harga diketahui semua butir pernyataan $r_{\text {hitung }}(0,670$ s.d. $0,659)>r_{\text {tabel }}(0,235)$ dengan nilai signifikasi 0,05 sehingga ke lima butir pernyataan pada variabel harga dinyatakan valid.

\begin{tabular}{|l|l|l|l|}
\hline $\begin{array}{l}\text { Pernyataa } \\
\mathrm{n}\end{array}$ & $\mathrm{r}_{\text {tabel }}$ & $\mathrm{r}_{\text {hitung }}$ & $\begin{array}{l}\text { Keteranga } \\
\mathrm{n}\end{array}$ \\
\hline Butir 11 & $\begin{array}{l}0,23 \\
5\end{array}$ & $\begin{array}{l}0,51 \\
0\end{array}$ & Valid \\
\hline Butir 12 & $\begin{array}{l}0,23 \\
5\end{array}$ & $\begin{array}{l}0,69 \\
0\end{array}$ & Valid \\
\hline Butir 13 & $\begin{array}{l}0,23 \\
5\end{array}$ & $\begin{array}{l}0,36 \\
1\end{array}$ & Valid \\
\hline Butir 14 & $\begin{array}{l}0,23 \\
5\end{array}$ & 0,64 & Valid \\
& 2 & \\
\hline Butir 15 & 0,23 & 0,57 & Valid \\
& 5 & 3 & \\
\hline
\end{tabular}

Sumber : Data primer yang diolah, 2019

Berdasarkan hasil uji validitas diatas dengan variabel tempat diketahui semua butir pernyataan $r_{\text {hitung }}(0,510$ s.d. $0,573)>r_{\text {tabel }}(0,235)$ dengan nilai signifikasi 0,05 sehingga ke lima butir pernyataan pada variabel tempat dinyatakan valid.

Variabel Promosi

\begin{tabular}{|l|l|l|l|}
\hline $\begin{array}{l}\text { Pernyata } \\
\text { an }\end{array}$ & $\mathrm{r}_{\text {tabel }}$ & $\mathrm{r}_{\text {hitung }}$ & $\begin{array}{l}\text { Keterang } \\
\text { an }\end{array}$ \\
\hline Butir 16 & 0,235 & 0,427 & Valid \\
\hline Butir 17 & 0,235 & 0,491 & Valid \\
\hline Butir 18 & 0,235 & 0,615 & Valid \\
\hline Butir 19 & 0,235 & 0,573 & Valid \\
\hline
\end{tabular}

\section{\begin{tabular}{|l|l|l|l|}
\hline Butir 20 & 0,235 & 0,668 & Valid \\
\hline
\end{tabular}}

Sumber : Data primer yang diolah, 2019

Berdasarkan hasil uji validitas

diatas dengan variabel promosi diketahui semua butir pernyataan $r_{\text {hitung }}$ $(0,427$ s.d. 0,668$)>r_{\text {tabel }}(0,235)$ dengan nilai signifikasi 0,05 sehingga ke lima butir pernyataan pada variabel promosi dinyatakan valid.

\section{Variabel Daya Saing}

\begin{tabular}{|l|l|l|l|}
\hline $\begin{array}{l}\text { Pernyata } \\
\text { an }\end{array}$ & $\mathrm{r}_{\text {tabel }}$ & $\mathrm{r}_{\text {hitung }}$ & $\begin{array}{l}\text { Keterang } \\
\text { an }\end{array}$ \\
\hline Butir 16 & 0,235 & 0,460 & Valid \\
\hline Butir 17 & 0,235 & 0,602 & Valid \\
\hline Butir 18 & 0,235 & 0,593 & Valid \\
\hline Butir 19 & 0,235 & 0,388 & Valid \\
\hline Butir 20 & 0,235 & 0,634 & Valid \\
\hline
\end{tabular}

Sumber : Data primer yang diolah, 2019

Berdasarkan hasil uji validitas diatas dengan variabel daya saing diketahui semua butir pernyataan $r_{\text {hitung }}$ $(0,427$ s.d. 0,668$)>r_{\text {tabel }}(0,235)$ dengan nilai signifikasi 0,05 sehingga ke lima butir pernyataan pada variabel daya saing dinyatakan valid.

Pengujian kualitas data dengan uji reliabilitas, dengan menggunakan rumus alpha dari Cronbach (Suharsimi Arikunto, 2010:171). Kriteria pengujiannya adalah jika $r_{\text {hitung }}$ lebih besar dari $r_{\text {tabel }}$ dengan taraf signifikan pada $\alpha=0,05$, maka instrumen tersebut adalah reliabel, sebaliknya jika $\mathrm{r}_{\text {hitung }}$ lebih kecil dari $\mathrm{r}_{\text {tabel }}$ maka instrumen tersebut adalah tidak reliabel. Hasil uji reliabilitas adalah tabel berikut :

Uji Realibitas

\begin{tabular}{|l|l|l|l|}
\hline Pernyataan & $\begin{array}{l}\text { Cronbach } \\
\text { Alpha }\end{array}$ & $\begin{array}{l}\mathrm{R} \\
\text { tabel }\end{array}$ & Keterangan \\
\hline Produk & 0,677 & 0,235 & Reliabel \\
\hline Harga & 0,584 & 0,235 & Reliabel \\
\hline Tempat & 0,452 & 0,235 & Reliabel \\
\hline Promosi & 0,438 & 0,235 & Reliabel \\
\hline Daya Saing & 0,375 & 0,235 & Reliabel \\
\hline
\end{tabular}

Sumber : Data primer yang diolah, 2019 
EKOBIS : Jurnal Ilmu Manajemen dan Akutansi

Vol. 8 No. 1, Juni 2020

ISSN : 2502-3055

e-ISSN : 2622-17

Berdasarkan tabel tersebut menunjukan bahwa variabel produk, harga, tempat, promosi dan daya saing memiliki data yang reliabel. Hal ini terlihat dari Cronbach Alpha lebih besar dari $r_{\text {tabel }}$. hasil pengujian asumsi klasik.

a. Uji Normalitas

Uji normalitas data dilakukan dengan menggunakan Test Normality Kolmogorov-Smirnov, menurut Singgih Santosa (2012:393) dasar pengambilan keputusan dilakukan berdasarkan probabilitas

(Asymtotic Significanted), yaitu jika probabilitas $>0,05$ maka distribusi dari model regresi adalah normal. Dan jika probabilitas < 0,05 maka distribusi dari model regresi adalah tidak normal.

Berdasarkan Test Normality Kolmogorov-Smirnov diperoleh nilai 0,128 atau $(12,8 \%)$ sehingga hasil dari pengujian ini berdistribusi normal.

a. Uji Multikolinearitas

Uji multikolinearitas bertujuan untuk menguji apakah model regresi ditemukan adanya korelasi antar variabel bebas. Indikator model regresi yang baik adalah tidak adanya korelasi antara variabel independen (Imam Ghozali, 2013:105). Pengujian multikolinearitas memiliki ketentuan bahwa Tolerance value < 0,10 atau VIF $>10$ : terjadi multikolinearitas dan Tolerance value $>0,10$ atau $\mathrm{VIF}<10$ : tidak terjadi multikolinearitas.

Hasil Uji Multikolinearitas

\begin{tabular}{|l|l|l|l|}
\hline & & & earitas \\
\hline Harga (X2) & 0,936 & 1,068 & $\begin{array}{l}\text { Bebas } \\
\text { Multikolin } \\
\text { earitas }\end{array}$ \\
\hline Tempat (X3) & 0,886 & 1,128 & $\begin{array}{l}\text { Bebas } \\
\text { Multikolin } \\
\text { earitas }\end{array}$ \\
\hline $\begin{array}{l}\text { Promosi } \\
\text { (X4) }\end{array}$ & 0,956 & 1,046 & $\begin{array}{l}\text { Bebas } \\
\text { Multikolin } \\
\text { earitas }\end{array}$ \\
\hline
\end{tabular}

Sumber : Data primer yang diolah, 2019

Dari tabel diatas dapat dilihat bahwa pernyataan dari variabel produk, harga, tempat dan promosi dalam penelitian ini adalah bebas multikolinearitas. Hal tersebut ditunjukan dengan nilai Tolerance value $>0,10$ atau $\mathrm{VIF}<10$.

b. Uji Heterokesdastisitas

Dalam persamaan regresi berganda perlu juga diuji mengenai sama atau tidak varian dari residual dari observasi yang satu dengan observasi yang lain. Jika residualnya mempunyai varian yang sama disebut terjadi homoskedastisitas dan jika variannya tidak sama atau berbeda disebut terjadi heteroskedastisitas. Persamaan regresi yang baik jika tidak terjadi heteroskedastisitas, Danang Sunyoto (2013:90).

Hasil Uji Heterokesdastisitas

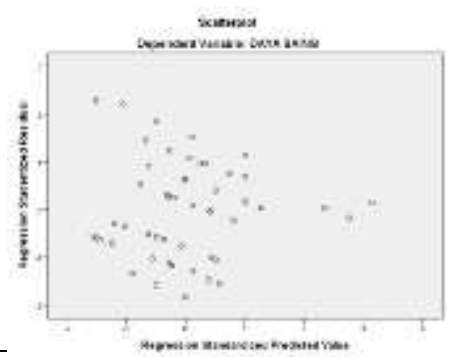

\begin{tabular}{|l|l|l|l|}
\hline Variabel & Tolerance & VIF & Ket \\
\hline Produk (X1) & 0,924 & 1,082 & $\begin{array}{l}\text { Bebas Sumber : Data primer yang diolah, } 2019 \\
\text { Multikolin }\end{array}$
\end{tabular}


Dari hasil gambar grafik diatas antara nilai sumbu $\mathrm{Y}$ (nilai $\mathrm{Y}$ yang diprediksi) dan sumbu $\mathrm{X}$ (nilai residual) menunjukan pola yang tidak jelas, serta titik menyebar diatas dan dibawah sumbu Y secara tidak teratur sehingga menunjukkan tidak terjadi heteroskedastisitas.

c. Uji Autokorelasi

Menurut Danang Sunyoto (2013:98) akibat dari adanya autokorelasi dalam model regresi, koefisien regresi yang diperoleh menjadi tidak efisien, artinya tingkat kesalahan prediksinya menjadi besar. Untuk menguji ada tidaknya autokorelasi, dari data residual terlebih dulu dihitung nilai statistik Durbin-Watson (D-W).

Hasil Uji Autokorelasi Model Summary ${ }^{\mathrm{b}}$

\begin{tabular}{|c|c|c|c|c|c|}
\hline $\begin{array}{l}\text { Mo } \\
\text { del }\end{array}$ & & $\begin{array}{l}\mathrm{R} \\
\text { Square }\end{array}$ & $\begin{array}{l}\text { Adjus } \\
\text { ted R } \\
\text { Squar } \\
\text { e }\end{array}$ & \begin{tabular}{|l} 
Std. \\
Erro \\
$\mathrm{r}$ of \\
the \\
Esti \\
mat \\
$\mathrm{e}$ \\
\end{tabular} & $\begin{array}{l}\text { Du } \\
\text { rbi } \\
\text { n- } \\
\mathrm{W} \\
\text { ats } \\
\text { on }\end{array}$ \\
\hline 1 & .418 & .174 & .101 & \begin{tabular}{|l|}
2.18 \\
8 \\
\end{tabular} & $\begin{array}{l}2.3 \\
83 \\
\end{array}$ \\
\hline
\end{tabular}

a. Predictors: (Constant), PROMOSI, PRODUK, HARGA, TEMPAT

b. Dependent Variable: DAYA SAING

Sumber : Data primer yang diolah, 2019

Dari tabel diatas diketahui bahwa

Durbin - Watson sebesar 2,383, dengan jumlah variabel independen empat dan jumlah sampel 50 dapat kita ketahui nilai $d_{L}$ sebesar 1,3779 dan $d_{U}$ sebesar 1,7214 dilihat dari tabel Durbin Watson. Jika $d_{U}<4-d_{U}$, maka dari hasil tersebut dapat dilihat bahwa nilai $d$ terletak di antara batas bawah $d_{L}$ dan batas atas $d_{U}$. Dengan hasil tersebut dapat disimpulkan bahwa tidak terjadi autokorelasi.

Pengujian Hipotesis Penelitian
Uji hipotesis digunakan untuk menguji ada tidaknya pengaruh antar variabel independen terhadap variabel dependen. Hasil uji hipotesis dari penelitian ini adalah:

Hasil uji parsial (uji t) dari pengujian ini adalah :

Hipotesa :

Ho: Produk, harga, tempat dan promosi secara parsial berpengaruh signifikan terhadap daya saing industri kerajinan tembaga Desa Tumang Kecamatan Cepogo Kabupaten Boyolali

Ha : Produk, harga, tempat dan promosi secara parsial tidak berpengaruh signifikan terhadap daya saing industri kerajinan tembaga Desa Tumang Kecamatan Cepogo Kabupaten Boyolaloi.

\section{Coefficients $^{\mathrm{a}}$}

\begin{tabular}{|c|c|c|c|c|c|}
\hline \multirow[b]{2}{*}{ Model } & \multicolumn{2}{|c|}{$\begin{array}{l}\text { Unstandardize } \\
\text { d Coefficients }\end{array}$} & \multirow{2}{*}{\begin{tabular}{|l}
$\begin{array}{l}\text { Standar } \\
\text { dized } \\
\text { Coeffic } \\
\text { ients }\end{array}$ \\
Beta \\
\end{tabular}} & \multirow[b]{2}{*}{$\mathrm{t}$} & \multirow[b]{2}{*}{ Sig. } \\
\hline & B & $\begin{array}{l}\text { Std. } \\
\text { Error }\end{array}$ & & & \\
\hline 1 (Constant) & 4.738 & 5.116 & & .926 & .359 \\
\hline PRODUK & .131 & .156 & .118 & .839 & .406 \\
\hline HARGA & .069 & .140 & .069 & .492 & .625 \\
\hline TEMPAT & .262 & .149 & .252 & 1.754 & .086 \\
\hline PROMOSI & .321 & .153 & .290 & 2.094 & .042 \\
\hline
\end{tabular}

a. Dependent Variable: DAYA SAING

Sumber : Data primer yang diolah, 2019

Dari tabel diatas maka dapat dijelaskan sebagai berikut :

a. Analisis terhadap produk

Berdasarkan tabel diatas diketahui nilai signifikan variabel produk sebesar 0,406>0,05 berarti produk tidak berpengaruh signifikan terhadap daya saing industri kerajinan tembaga di Desa Tumang Kecamatan Cepogo, Kabupaten Boyolali. Artinya variabel produk tidak mempengaruhi daya saing.

b. Analisis terhadap harga

Berdasarkan tabel diatas diketahui nilai signifikan variabel harga 
sebesar 0,625 >0,05 berarti harga tidak berpengaruh secara signifikan

terhadap daya saing industri kerajinan tembaga di Desa Tumang Kecamatan Cepogo, Kabupaten Boyolali. Artinya variabel harga tidak mempengaruhi daya saing.

c. Analisis terhadap tempat

Berdasarkan tabel diatas diketahui nilai signifikan variabel tempat sebesar $0,086>0,05$ berarti tempat tidak berpengaruh secara signifikan terhadap daya saing industri kerajinan tembaga di Desa Tumang Kecamatan Cepogo, Kabupaten Boyolali. Artinya variabel tempat tidak mempengaruhi daya saing.

d. Analisis terhadap promosi

Berdasarkan tabel diatas diketahui nilai signifikan variabel promosi sebesar $0,042<0,05$ berarti promosi berpengaruh secara signifikan terhadap daya saing industri kerajinan tembaga di Desa Tumang Kecamatan Cepogo, Kabupaten Boyolali. Artinya variabel promosi mempengaruhi daya saing.

b. Uji Simultan (Uji F)

Hipotesa :

$\mathrm{H}_{\mathrm{o}} \quad$ : Produk, harga, tempat dan promosi secara simultan berpengaruh signifikan terhadap daya saing industri kerajinan tembaga Desa Tumang Kecamatan Cepogo Kabupaten Boyolali.

$\mathrm{H}_{\mathrm{a}} \quad$ : Produk, harga, tempat dan promosi secara simultan tidak berpengaruh signifikan terhadap daya saing industri kerajinan tembaga Desa Tumang Kecamatan Cepogo Kabupaten Boyolali.
ANOVA $^{\mathrm{a}}$

Hasil pengujian simultan (Uji F)

\begin{tabular}{|l|l|l|l|l|l|}
\hline Model & $\begin{array}{l}\text { Sum of } \\
\text { Squares }\end{array}$ & Df & $\begin{array}{l}\text { Mean } \\
\text { Squar }\end{array}$ & F & $\begin{array}{l}\text { Si } \\
\text { g. }\end{array}$ \\
\hline $\begin{array}{l}1 \\
\text { Regressi } \\
\text { on }\end{array}$ & 45.523 & 4 & 11.38 & 2.3 & .06 \\
$\quad \begin{array}{l}\text { Residual } \\
\text { Total }\end{array}$ & 215.357 & 45 & 4.786 & 78 & $6^{\text {b }}$ \\
\hline
\end{tabular}

a. Dependent Variable: DAYA SAING

b.Predictors: (Constant),

PRODUK, HARGA, TEMPAT

Sumber : Data primer yang diolah, 2019

a. Taraf Signifikasi

Taraf signifikasi adalah 0,05 dan menentukan taraf $F_{\text {hitung }}$ dan $F_{\text {tabel }}$. Dari hasil pengujian didapatkan :

- $\mathrm{F}_{\text {hitung }}$ adalah 2,378

- $\mathrm{F}_{\text {tabel }}$ dicari melalui tabel statistik pada signifikasi 0,05 dimana $\mathrm{df}_{1}$ $=4$ dan $\mathrm{df}_{2}=45$ ditemukan bahwa $F_{\text {tabel }}$ adalah 2,58

b. Pengambilan keputusan

Jika $\mathrm{F}_{\text {hitung }}<\mathrm{F}_{\text {tabel }}$ maka $\mathrm{H}_{\mathrm{o}}$ diterima dan $\mathrm{H}_{\mathrm{a}}$ ditolak

Jika $\mathrm{F}_{\text {hitung }}>\mathrm{F}_{\text {tabel }}$ maka $\mathrm{H}_{\mathrm{o}}$ ditolak dan $\mathrm{H}_{\mathrm{a}}$ diterima

c. Kesimpulan

Hasil Uji $\mathrm{F}$ diperoleh $\mathrm{F}_{\text {hitung }}$ sebesar 2,378 (pada signifikasi $0,000<$ 0,05 ) yang berarti bahwa produk, harga, tempat dan promosi tidak berpengaruh secara simultan terhadap daya saing industri kerajinan tembaga di Desa Tumang Kecamatan Cepogo Kabupaten Boyolali.

Regresi Linear Berganda untuk mengetahui faktor-faktor yang mempengaruhi terhadap daya saing. Hasil dari analisis regresi linier berganda adalah sebagai berikut : 
EKOBIS : Jurnal Ilmu Manajemen dan Akutansi

Vol. 8 No. 1, Juni 2020

ISSN : 2502-3055

e-ISSN : 2622-17

Hasil Uji Regresi Linear Berganda

Coefficients $^{\text {a }}$

\begin{tabular}{|c|c|c|c|c|c|}
\hline \multirow[b]{2}{*}{ Model } & \multicolumn{2}{|c|}{$\begin{array}{l}\text { Unstandardized } \\
\text { Coefficients }\end{array}$} & \multirow{2}{*}{\begin{tabular}{|l|}
$\begin{array}{l}\text { Standardized } \\
\text { Coefficients }\end{array}$ \\
Beta \\
\end{tabular}} & \multirow[b]{2}{*}{$t$} & \multirow[b]{2}{*}{ Sig. } \\
\hline & B & $\begin{array}{l}\text { Std. } \\
\text { Error }\end{array}$ & & & \\
\hline 1 (Constant) & 4.738 & 5.116 & & .926 & .359 \\
\hline PRODUK & .131 & .156 & .118 & .839 & .406 \\
\hline HARGA & .069 & .140 & .069 & .492 & .625 \\
\hline TEMPAT & .262 & .149 & .252 & $\begin{array}{l}1.75 \\
4\end{array}$ & .086 \\
\hline PROMOSI & .321 & .153 & .290 & $\begin{array}{l}2.09 \\
4\end{array}$ & .042 \\
\hline
\end{tabular}

a. Dependent Variable: DAYA SAING

Sumber : Data primer yang diolah, 2019

Berdasarkan hasil analisis regresi linier berganda pada tabel diatas diperoleh persamaan regresi yaitu :

$$
\begin{aligned}
Y & =\alpha+b_{1} X_{1}+b_{2} X_{2}+b_{3} X_{3}+b_{4} \\
& X_{4}+\varepsilon \\
& =4,738+0,131 X_{1}+0,069 X_{2} \\
& +0,262 X_{3}+0,321 X_{4}+\varepsilon
\end{aligned}
$$

Dari hasil data diatas, maka dapat dijelaskan sebagai berikut :

1. $\mathrm{X}_{1}=$ Nilai koefisien variabel produk menunjukkan koefisien yang positif sebesar 0,131 dengan demikian diketahui bahwa produk secara signifikan tidak dapat meningkatkan daya saing.

2. $\mathrm{X}_{2}=$ Nilai koefisien variabel harga menunjukkan koefisien yang positif sebesar 0,069 dengan demikian diketahui bahwa harga secara signifikan tidak dapat meningkatkan daya saing.

3. $X_{3}=$ Nilai koefisien variabel tempat menunjukkan koefisien yang positif sebesar 0,262 dengan demikian diketahui bahwa tempat secara signifikan tidak dapat meningkatkan daya saing.

4. $\mathrm{X}_{4}=$ Nilai koefisien variabel promosi menunjukkan koefisien yang positif sebesar 0,321 dengan demikian dapat diketahui bahwa promosi secara signifikan dapat meningkatkan daya saing.

- Produk

Uji Koefisien Determinasi $\left(\mathrm{R}^{2}\right)$ dari hasil regresi linier berganda meneunjukan seberapa besar variabel dependen (daya saing) dipengaruhi oleh variabel independen (produk, harga, tempat dan promosi). Hasil uji koefisien determinasi $\left(\mathrm{R}^{2}\right)$ dapat dilihat pada tabel berikut:

Hasil Uji Koefisien Determinasi $\left(\mathrm{R}^{2}\right)$

Model Summary ${ }^{\mathrm{b}}$

\begin{tabular}{|l|l|l|l|l|l|}
\hline Model & R & R Square & $\begin{array}{l}\text { Adjusted } \\
\text { R Square }\end{array}$ & $\begin{array}{l}\text { Std. } \\
\text { Error }\end{array}$ & DW \\
\hline 1 & $.418^{\mathrm{a}}$ & .174 & .101 & 2.188 & $\begin{array}{l}2.38 \\
3\end{array}$ \\
\hline
\end{tabular}

a. Predictors: (Constant), PROMOSI, PRODUK, HARGA, TEMPAT

b. Dependent Variable: DAYA SAING

Sumber : Data primer yang diolah, 2019

Berdasarkan data diatas, diperoleh Koefisien determinasi $\left(\mathrm{R}^{2}\right)$ sebesar 0,174 atau $(17,4 \%)$ daya saing industri tembaga di Desa Tumang Kecamatan Cepogo Kabupaten Boyolali dipengaruhi oleh variabel produk, harga, tempat dan promosi. Sedangkan $82,6 \%$ dipengaruhi oleh variabel lain yang tidak dimasukkan dalam penelitian ini. 
Dari analisis data di atas dihasilkan nilai-nilai yang digunakan untuk membuktikan hipotesis dari penelitian, antara lain:

- Produk

Berdasarkan hasil analisis regresi berganda dengan uji t menunjukan nilai sig. 0,406 $>0,05$ berarti bahwa variabel produk tidak berpengaruh signifikan terhadap daya saing.

- Harga

Berdasarkan hasil analisis regresi berganda dengan uji t menunjukan nilai sig. $0,625>0,05$ berarti bahwa harga tidak berpengaruh signifikan terhadap daya saing.

- Tempat

Berdasarkan hasil analisis regresi berganda dengan uji t menunjukan nilai sig. $0,086>0,05$ berarti bahwa tempat tidak berpengaruh signifikan terhadap daya saing

- Promosi

Berdasarkan hasil analisis regresi berganda dengan uji t menunjukan nilai sig. $0,042<0,05$ berarti bahwa promosi berpengaruh signifikan terhadap daya saing

Dari hasil diatas diketahui bahwa secara parsial promosi berpengaruh positif secara signifikan terhadap daya saing. Sedangkan produk, harga dan tempat tidak berpengaruh secara signifikan terhadap daya saing.

b. Hipotesis Kedua

Dari hasil uji simultan (uji f) dari penelitian ini di ketahui bahwa :

Hasil Uji $F$ diperoleh $F_{\text {hitung }}$ sebesar 2,378 (pada signifikasi $0,000<$ 0,05 ) yang berarti bahwa produk, harga, tempat dan promosi secara simultan tidak berpengaruh terhadap daya saing industri kerajinan tembaga di Desa Tumang Kecamatan Cepogo Kabupaten Boyolali.

c. Koefisien Determinasi

Sedangkan nilai koefisien determinasi $\left(\mathrm{R}^{2}\right)$ sebesar 0,174

\section{a. Hipotesis Pertama}

Dari hasil uji parsial (uji t) dari penelitian ini diketahui bahwa :

memiliki pengertian bahwa produk, harga, tempat dan promosi secara bersama-sama mampu mempengaruhi variabel daya saing sebesar $17,4 \%$ selebihnya $82,6 \%$ dipengaruhi oleh variabel lain yang tidak dimasukkan dalam penelitian ini.

Daya saing industri kerajinan tembaga di Desa Tumang Kecamatan Cepogo Kabupaten Boyolali dipengaruhi oleh berbagai faktor lain yang tidak dimasukkan di dalam penelitian ini misalnya permintaan pasar, sumber daya manusia (SDM), teknologi, inovasi dan peran pemerintah.

\section{KESIMPULAN}

Berdasarkan hasil penelitian yang telah dilakukan tentang pengaruh bauran pemasaran terhadap daya saing industri kerajinan tembaga di Desa Tumang Kecamatan Cepogo Kabupaten Boyolali dapat disimpulkan sebagai berikut :

1. Secara parsial produk tidak berpengaruh signifikan terhadap daya saing industri kerajinan tembaga di Desa Tumang Kecamatan Cepogo Kabupaten Boyolali.

2. Secara parsial harga tidak berpengaruh signifikan terhadap daya saing industri kerajinan tembaga di Desa Tumang Kecamatan Cepogo Kabupaten Boyolali.

3. Secara parsial tempat tidak berpengaruh signifikan terhadap daya saing industri kerajinan tembaga di Desa Tumang Kecamatan Cepogo Kabupaten Boyolali. 
EKOBIS : Jurnal Ilmu Manajemen dan Akutansi

Vol. 8 No. 1, Juni 2020

4. Secara parsial promosi berpengaruh positif secara signifikan terhadap daya saing industri kerajinan tembaga di Desa Tumang Kecamatan Cepogo Kabupaten Boyolali.

\section{DAFTAR PUSTAKA}

Alma, Buchari, 2004, Manajemen Pemasaran dan Pemasaran Jasa, Cetakan Keenam, Alfabeta, Bandung.

Arikunto, Suharsimi, 2010. Prosedur Penelitian Suatu Pendekatan Praktek. Jakarta: Rineka Cipta.

Armstrong dan Kotler. 1999. Prinsip- Prinsip Pemasaran. Jakarta: Erlangga

Asmara, Anugerah Yuka dan Rahayu, Sri.2015. Meningkatkan daya saing industry kecil menengah melalui inovasi dan pemanfaatan jaringan sosial: pembelajaran dari klaster industri software di india. Jurnal. Pappiptek LIPI

Assauri Sofyan. 2002. Manajemen Pemasaran (dalam konsep dan strategi). Jakarta : RajawaliGrafindo.

Assauri, Sofjan, 2007. Manajemen Pemasaran, Rajawali Pers, Jakarta. Badan Pusat Statistik (BPS). Pengertian Industri.

(http://www.gurupendidikan.com/20 -pengertian-industri-menurut-paraahli/html)

Basu Swasta DH., dan T. Hani Handoko. 1997. Manajemen

Pemasaran Modern, Yogyakarta: Liberty.

Basu Swastha Dharmmesta dan T. Hani Handoko.(2000).

Manajemen Pemasaran, Analisis Perilaku Konsumen. Yogyakarta: BPFE.

Basu Swastha, DH dan Irawan. 1990. Manajemen Pemasaran Modern. Yogyakarta: Liberty.
5. Produk, harga, tempat dan promosi secara simultan tidak berpengaruh terhadap daya saing industri kerajinan tembaga.

Basu, Swastha dan Irawan, (1999), Manajemen Pemasaran Modern, Edisi 2. Yogyakarta : Liberty.

Catur E. Rismiati - Ig. Bomdan Suratno. 2006. Pemasaran Barang dan Jasa. Yogyakarta : Kanisius.

Dr. H. Ade Komarudin, MH. 2014. Politik Hukum Integratif UMKM. RMBooks.

Ghozali, Imam. 2013. Aplikasi Analisis Multivariate dengan Program SPSS. BP Semarang : Universitas Diponegoro.

Handoko, T.Hani dan Basu Swastha Dharmmesta. 2000. Manajemen Pemasaran: Analisa Perilaku Konsumen Edisi Pertama. Yogyakarta: BPFE.

Harper W. Boyd, dkk. 2000. Manajemen Pemasaran Suatu Pendekatan Strategis dengan Orientasi Global. Jakarta : Erlangga. http://www.seputarpengetahuan.co.i d (diakses pada tanggal 20 juni 2019)

Kotler,Philip dan Gary Armstrong.2005. Prinsip-prinsip pemasaran. Jakarta : Erlangga.

Kotler, Philip \& Keller. Manajemen Pemasaran Edisi Ketigabelas Jilid 1.Jakarata: Erlangga.

Kotler dan Keller. 2009. Manajemen Pemasaran. Jilid I. Edisi ke 13. Jakarta: Erlangga.

Kotler, Philip \& Kevin L. Keller. 2012. Marketing Managemen, 14th edition.New Jersey: Prentice Hall Kotler, Philip dan gary Armstrong, 2003, Dasar-dasar Pemasaran, Jilid 1, Edisi Kesembilan, Jakarta: PT. Indeks Gramedia

Kotler, Philip, (1994), Marketing Management ; Analysis, Planning, Implementation and Control (8th 
EKOBIS : Jurnal Ilmu Manajemen dan Akutansi

Vol. 8 No. 1, Juni 2020

ISSN : 2502-3055

ed), International Edition, Englewood Cliffs, Prentice Hall, New Jersey.

Kotler, Philip. (1993). Manajemen Pemasaran: Analisis, Perencanaan, Implementasi dan Pengendalian,

Implementasi dan Kontrol. Jakarta : Prenhallindo.

Kotler, Philip. 1999. Manajemen Pemasaran. Jilid II. Edisi Milenium. Jakarta: PT. Prenhallindo.

Kotler, Philip; Armstrong, Garry, 2008. Prinsip-prinsip Pemasaran, Jilid 1, Jakarta: Erlangga

Kuncoro, Mudrajad. 2007. Ekonomika Industri Indonesia : Menuju Negara Industri Baru 2030?.Yogyakarta: Andi Publisher Muhardi. 2007. Strategi Operasi Untuk Keunggulan Bersaing. Graha Ilmu.

Singarimbun, Masri dan Sofian Effendi, 2002. Metode Penelitian Survai. Jakarta: LP3ES.

Stanton, William J. 2008. Fundamentalbof Marketing 10 Edition. New York : Mc Graw-Hill International Edition.

Sugiyono. 2013. Metodologi Penelitian Kuantitatif, Kualitatif Dan $R \& D$. Bandung : Alfabeta:.

Sugiyono, (2008). Metode Penelitian Kunatitatif Kualitatif dan $R \& D$. Bandung Alfabeta.

Sugiyono, 2006, Statistika Untuk Penelitian, Cetakan Ketujuh, Bandung: CV. Alfabeta.

Sugiyono. 2006. Metode Penelitian Pendidikan; Pendekatan Kuantitatif dan Kualitatif dan $R \& D$. Bandung: Alfabeta

Sugiyono. 2016. Metode Penelitian Kuantitatif, Kualitatif dan Kombinasi. Bandung: Alfabeta

Sunyoto, Danang. 2013. Metodologi Penelitian Akuntansi. Bandung: PT Refika.

Tambunan, Tulus T.H. 2002. Usaha Kecil dan Menengah di Indonesia:
(Diterjemahkan oleh Adi Zakaria Afif). Yogyakarta : Fakultas Ekonomi Universitas Indonesia.

Kotler, Philip. (1995). Manajemen

Pemasaran, Analisis, Perencanaan,

Beberapa Isu-Isu Penting. Jakarta : Salemba Empat.

Wibowo, Dimas Hendika Dan Arifin, Zainul Serta Sunarti. 2015. Analisis Strategi Pemasaran Untuk Meningkatkan Daya Saing Umkm (Studi Pada Batik Diajeng Solo). Jurnal. Malang: Universitas Brawijaya. 